\title{
Transformation and Upgrading of Tourism Consumption Structure in Guangdong Province
}

\author{
Yi Liu, Lu Zhang \\ Jinan University, Guangzhou, China \\ Email: 13872609763@163.com
}

How to cite this paper: Liu, Y. and Zhang, L. (2018) Transformation and Upgrading of Tourism Consumption Structure in Guangdong Province. American Journal of Industrial and Business Management, 8, 1229-1238. https://doi.org/10.4236/ajibm.2018.85083

Received: April 13, 2018

Accepted: May 18, 2018

Published: May 21, 2018

Copyright $\odot 2018$ by authors and Scientific Research Publishing Inc. This work is licensed under the Creative Commons Attribution International License (CC BY 4.0).

http://creativecommons.org/licenses/by/4.0/

\begin{abstract}
Tourism consumption structure is one of the most important standards to measure the tourism development of a country or region. Based on the domestic tourism consumption structure statistics of Guangdong Province, this article summarized the problems of domestic tourism consumption and put forward the strategies to optimize tourism consumption structure in Guangdong Province.
\end{abstract}

\section{Keywords}

Guangdong Province, Tourism Consumption Structure, Transformation and Upgrading

\section{Definition of Tourism Consumption Structure, Transformation and Upgrading}

After nearly 30 years development, the expansion of Chinese tourism, which used to focus on number and scale, now replaced by the growth of quality and benefit gradually. Hence it's important to research on tourism consumption structure. Tourism consumption structure refers to a proportional relation of various types of tourism commodities, including material, spiritual and service goods consumed by tourists. According to classification on meeting different levels of needs, tourism consumption can be divided into the means of subsistence, enjoyment and development consumption. According to classification on meeting different purposes, tourism consumption can be divided into eating, living, transportation, tour, shopping and entertainment, total six aspects. From the importance of tourist consumption on tourism activities, tourism consumption can be divided into the basic tourism consumption and the non-basic tourism consumption [1]. Basic tourism consumption is necessary and basically sta- 
ble for a tourist activity, such as the consumption in the field of transportation, accommodation, catering and tour. Non-basic tourism consumption refers to consumption that is nonessential for each tourist activity, such as shopping, entertainment, communications, medical and etc. The proportional relation of basic tourism consumption and non-basic tourism consumption, namely tourism consumption structure is one of the most important reference indexes to measure tourism and economic development level of a country or region [2]. Normally, the lower of the tourism development level means the lower of tourist consumption, and the higher of basic tourism consumption spending, conversely, the higher of non-basic consumer spending. Based on the historical materials of Chinese domestic tourism sampling survey, this article will divide domestic tourism consumption demand into long distance transportation, accommodation, catering, traffic in the city, the scenic spot tour, post and communications, entertainment, shopping and other services, total nine aspects (hereinafter called as the "nine aspects tourism consumption").

Tourism industry transformation, that is, via the transformation in the form of development mode, realizing the changes and adjustments to the existing tourism industry structure, which are focusing on scale expansion to pay equal attention on benefit and efficiency, extensive to intensive development, economic function to comprehensive function [3]. Transformation and upgrading are an inevitable trend for the development of tourism industry, also is an inevitable choice for the tourism industry to realize sustainable development. When the tourism industry develops to a certain scale and degree, it's required to make changes and adjustments on the development pattern and direction. Overall, our country's tourism has been three stages of development, from the solo of inbound tourism during the period of reform and opening up, to rapid development stage with elements agglomeration of tourism industry, to the diversified and personalized development of tourism industry in today's society [4]. Tourism industry in our country has entered the third development opportunity period, which is forced by tourism industry development stage and demand change. With the rapid development of tourism market and changes on international environment, as a major tourism province, it's an inevitable trend for Guangdong to improve tourism industry structure and tourism product quality, hence the study on tourism consumption structure and law of development of Guangdong province are significant and helpful to reveal tourism industry development status, adjust and optimize tourism industry structure, promote tourism industry transformation and upgrading.

\section{Present Situation of Tourism Industry in Guangdong Province}

Guangdong as the forefront of reform and opening up, walks in the forefront of the national tourism. Total tourism income have ranked among the top nationwide for a long time, occupied a quarter of the proportion in the national tourism, and created a number of the first. 


\subsection{Tourism Has Become the Pillar Industry of Guangdong Province}

Since 1994, foreign exchange learning, tourism revenues, the number of inbound visitors and other tourism major economic indicators of Guangdong tourism have ranked among the top nationwide. According to Guangdong tourism statistics, Guangdong province received overnight tourists number 444 million, with year-on-year growth of 14.95 percent. Tourism revenue 1199.3 billion yuan in 2017, with year-on-year growth of 11.4 percent [5].

\subsection{More Rich in Tourism Resources}

The overall advantages of complete resources category, good combination, reasonable distribution makes Guangdong province one of the most important tourist destination across the country.

\subsubsection{Tourism Facility}

Guangdong province as one of the earliest provinces starting tourism development, have a more mature tourism industry compared with others. By the end of 2014, hotel number in Guangdong is 15926, of which are 119 of five stars and 892 of three stars or above: total 1,481,397 beds, room occupancy rate of $58.4 \%$, and 1810 travel agencies, 52,418 travel agency employees [5].

\subsubsection{Scenic Spots}

Guangzh Until 2014, Guangdong own 9 national AAAAA scenic areas and 63 national AAAA scenic spot [5], ou chime-long tourist resort and Shenzhen OCT tourist resort. Guangdong province is in tropical and subtropical climate, with rich ecological tourism resources, mainland coastline of 3368 kilometers, among the first in the nation, there are more than 30 coastal beaches and more than 10 beautiful sea scenic spots. Guangdong province has been found more than 300 hot springs ranking third in China only after Tibet and Yunnan. Tourism scenic area is rich in Guangdong province. Taking Guangzhou city for example, the Chinese tourism development report 2014 pointed out that 15 deputy provincial cities in China, the tourism comprehensive competitiveness of Guangzhou ranking the first. According to the weighted calculation results from famous international businesses group Forbes, considering the number of inbound tourism, domestic tourism, tourist foreign exchange revenue, domestic tourism income, the number of hotels and scenic spots in AAAA or above, Guangzhou ranked fourth only after Beijing, Shanghai and Chongqing in China. Tourism market in Guangdong is prosperous.

\section{The Main Issues in Guangdong Tourism Consumption Structure}

Starting in the 1980s, Guangdong began to develop the domestic tourism, tourism product developing rapidly. Into the 1990s, tourism products represented by theme park began to flourish. With the development of tourism market and di- 
versification of consumer demand, the tourists focus on leisure tourism products, and Guangdong tourism products also transform to theme products, holiday leisure products and personalized products. However, Guangdong's experience on participation tourism products is still relatively less, "entertainment" and "purchase" development lags behind, holding a small proportion in tourist consumption. At present the tourism product structure is unmatched with rich tourism resources, it's required to adjust tourism product structure. This article analyzes the issues existing in the tourism consumption structure of Guangdong from three aspects: consumption structure, product structure and tourism commodity development.

\subsection{Imbalance between Basic and Non-Basic Tourism Consumption}

Tourist shopping consumption proportion in overall tourism consumption is a dominant index to reflect if tourism consumption structure is reasonable [6]. Statistical analysis of sample survey data shows that in 2014, the proportion of basic tourism consumption in Guangdong is on the high side, non-basic tourism consumption is low and the tourist consumption level is generally low. In the basic consumption, accommodation is firmly first, accounting for $18.6 \%$, catering and traffic are in second and third place respectively, including diet costs accounted for $16.9 \%$, traffic is $15.9 \%$, scenic tour is $8.9 \%$, shopping is $24.6 \%$, entertainment is $10.7 \%$, others are $4.4 \%$. Domestic basic tourism consumption including catering, accommodation, traffic and travel accounted for $60.3 \%$, non-basic tourism consumption growth is necessary and required. At present, tourism shopping consumption in developed countries and regions takes more than $60 \%$ of total tourist expenditure, in the domestic city with high level development of tourism shopping it's about $40 \%$ of total tourists expenditure, however Guangdong tourists shopping consumer spending accounts for only $24.6 \%$ of the total, which is a big gap compared with many international and domestic tourism developed cities.

\subsection{Tourism Consumption Per Capita Is Low}

Guangzhou is main port city for Hong Kong, Macao and Taiwan compatriots entering mainland China, although the tourist number in Guangzhou is very large, the residence time is not long and tourism consumption per capita is not high. In 2014, residence time is about 3 and a half days, overnight visitors cost is 3610 yuan per capita. However, compared with the 4200 per capita tourist spending in Beijing, Guangdong province's tourism per capita consumption is lower.

\subsection{Tourism Product Structure Is Unreasonable}

Tourism product refers to the sum of the products and services consumed in tourism activities, including in food, accommodation, transportation, traveling, shopping and entertainment fields [7]. According to the survey of the domestic 
tourists in Guangdong sampling data in 2014, visitors come to Guangdong for leisure vacation accounted for $39.5 \%$, besides $25 \%, 7.2 \%, 16.2 \%, 5.8 \%, 0.38 \%$, $1.32 \%$ of sightseeing, visiting relatives, business activities, attending meeting, religious worship, culture exchange respectively and $4.6 \%$ for other purposes. When choosing accommodation type, 69.4\% domestic tourists would choose star-rated hotels, $15.8 \%$ would choose the guest house, $11.1 \%$ would choose to live in home, the minimum ratio are relatives and friends own holiday home and other accommodation, $1.9 \%$ and $1.8 \%$, respectively, which reflects the low levels of tourism product structure of Guangdong province.

\section{Analysis of Transformation and Upgrading of Consumption Structure in Guangdong (SWOT Analysis)}

\subsection{Strengths}

\subsubsection{District Advantage}

Guangdong is one of the most important channels and tourist destinations for passengers, located in the south of Nanling, South China Sea. External close to Hong Kong, Macao and Southeast Asia, the Pearl River Delta regional platforms and many ports offer convenient transportation. Guangdong as the tourism destination with visitors from more than 80 countries and regions, carry out the border tourism with southeast Asian countries and Hong Kong, Macao and Taiwan tourism planning are expanding.

\subsubsection{Tourism Industry Structure Optimizing Obviously}

Tourism product system and industry elements improve continuously, modern tourism industry develops rapidly, tourist travel, accommodation, catering, scenic areas, business and entertainment service are in all-round development. Coastal tourism and ecological industrial park construction, tourism development in northwest area of Guangdong are further speeding up. Shanwei, Zhanjiang and other three provincial seaside tourism industrial park are developing rapidly. In addition, the provincial tourism bureau of statistics show that with the help of tourism fair, tourism culture festival, Guangdong held more than 80 performances of various kinds of tourism investment promotion activities with contract amount more than $\$ 240$ billion in 2013 .

\subsubsection{Policy Support}

"Tourism law" and the implementation of the national tourism and leisure programs, promote the market standardization and expanding the tourist market. Solving the problem of the absence of market rules, make a better balance of tourists and operator's responsibility, right and benefit relations, which will provide powerful basis for managing the tourism market order [8]. With the full implementation of the national tourism and leisure program paid vacation system put forward, it play a leading role in supporting the development of the whole national tourism leisure "695". Tourism industry policy support system improves constantly. At the provincial level, since Guangdong tourism's initial 
development, has issued the "regulations on the administration of tourism in Guangdong province", "Guangdong province tourism administration of the government information disclosure work way", "issued by the general office of the Guangdong people's government of Guangdong province to implement the" tourism law of the People's Republic of China", key task division scheme of notice, the people's government of Guangdong province about "county of Guangdong province tourism industry management interim provisions" on approval. Guangdong tourism policy system supports the development of industrial transformation and strengthen gradually.

\subsection{Weaknesses}

\subsubsection{Tourism Product Homogeneity and Lack of Market Competitiveness}

Tourism image is not sharp, which is disadvantage for the development of Guangdong tourism and not adapted with tourism strong province target. Guangdong lacks of well-known brand in the world. Although chime-long tourist resort won a great reputation through cooperation with Hunan satellite TV, other scenic spot such as Shenzhen OCT and splendid China has been slowly out of the sight of people, and some of the scenic area such as Danxia mountain world geological park is easy to be replaced due to the lack of publicity, which are far from Zhangjiajie, Yuntai mountain in domestic reputation. Guangdong tourism is characterized by Lingnan culture, however tourism products with Lingnan characteristic are single, lacking of scale and reputation.

\subsubsection{Tourism Industry Remains to Be Further Standardized}

Guangdong tourism has experienced the development before specifications. Guangdong province is located in the coastal and tourism developed early, supply and demand are imbalance, which causing a vicious cycle of Guangdong tourism industry in many ways. Part of travel agency service in Hong Kong and Macao tourist without, substantial and effective guide training system leading to irregularities such as zero inclusive-fee, none comprehensive service and guide kickbacks, which damaged tourism image of Guangdong.

\subsection{Opportunities}

First of all, China has published a series of policies and measures on expanding domestic demand, adjusting the economic structure, accelerating the development of service industry to create a favorable policy environment for tourism development. The state council has defined tourism as "strategic pillar industry of national economy" and "modern service industry", the great pattern of tourism industry and related industrial convergence development formed gradually. The tourism industry will gradually highlights its status.

Secondly, upgrade of residents' consumption structure laid a solid foundation for the transformation and upgrading of consumption structure of tourism industry in Guangdong. Guangdong's per capita GDP is close to $\$ 10,000$ at the 
end of "Twelfth five-year", according to research shows that when a country own more than $\$ 3000$ per capita GDP, leisure consumption will enter the popularization stage, when more than $\$ 5000$, leisure consumption will enter a rapid growth.

Thirdly, Guangdong regional economic integration accelerating will vigorously promote the internationalization process of tourism in Guangdong. In the next decade, Guangdong, Hong Kong and Macao will cooperate in many areas such as economy, society, culture and life, which are helpful for developing international tourism market in Guangdong.

Finally, information spread will accelerate the development of tourism industry.

\subsection{Threats}

\subsubsection{The Tourism Market Competition}

Transformation and upgrading put forward higher requirements to the level and quality of Guangdong tourism industry development. Tourism has become the world's most dynamic and potential industries in national economy, more and more provinces and cities implement national tourism development strategy to lead and drive the economic development, formulate the corresponding development plan, intensify promotion such as visa facilitation incentives to expand the international market. At the same time, after the state council published "the development of tourism opinion", tourism development momentum of many provinces is very strong, competing with Guangdong in formed products, market, investment, talent and brand etc. Guangdong tourism industry will develop at a higher level and face more fierce market competition.

\subsubsection{The Challenge for the Sustainable Development of Tourism Resources}

From the whole process of the development of Chinese tourism, the tourism resources sustainable development challenges mainly displays in following aspects, most of scenic spots only focus on economic interest, exploit tourism resources blindly, tourism resources protection consciousness is weak. In the process of development and utilization of resources in Guangdong tourism industry also exist same issues, and in combined with the lack of scientific planning, destruction happens occasionally.

\subsubsection{The Challenges for Tourism Market Demand Diversification}

With the development of economic and cultural life level, people in travelling have a higher demand at spirit level, pay more attention and emphasis on tourism experience, participation, hope themselves realizing the history and inherit national culture [9]. As a consequence, it put forward a higher request on tourist image and service quality of tourist destination, besides, travel demand showed high diversity and hierarchical .High quality and comprehensive tourism products are required to continuously meet the needs of the consumers.

Generally speaking, the advantages of Guangdong tourism consumption 
structure upgrading outweigh the disadvantages, opportunities outweigh the challenges.

\section{Suggestions}

\subsection{Optimizing Structure of Tourism Products}

From basic tourism consumption situation in Guangdong, the lag of tourism product development level restricts tourism consumption structure optimization. It's urgent to speed up the tourism product structure adjustment, enrich the content and connotation of tourism products.

First of all, in the tourism product element structure, the growth space of non-basic tourism consumption is larger than basic tourism consumption, strengthening the construction of non-basic tourism products is helpful for tourism economic benefit ascension: on the one hand, we should enrich tourist goods, improve its quality, especially pay attention to special tourism souvenir and develop tourism special local product, change the status quo of tourism machine-made, manufactured goods, at the same time, regulate the behavior of sales, eliminate non-standard phenomenon; on the other hand, we should develop projects with strong local flavor and appeal, participation experience of high-quality entertainment, what's more, develop reasonably of food, accommodation, transportation, traveling, shopping, entertainment and the proportion of each individual product.

Secondly, shopping and entertainment consumption level is low. Local government should actively support the development of shopping and entertainment products, give preferential policies properly.

Thirdly, it is required to adjust the policy of tourism product structure, strengthen the exploitation of tourism resources, according to the characteristics of the tourism resources to carry out the diversified and multi-level tourism activities, enrich the content of tourism consumption spirit, create excellent tourist products, break the traditional structure of single tourism product system, and gradually perfect sales and after-sales service, to meet the consumption demand of tourists.

Finally, developing the special tourism products on the basis of traditional tourism products. Tourism product structure of our country is unreasonable for a long time, which gives priority to tourism products in sightseeing-type, leading to excessive proportion of urban residents for purpose of tourists, entertainment and shopping consumption ratio is low and tourism economic efficiency is not high. Therefore, we should vigorously develop the holiday tourism, folk tourism, sports, photography, shopping tourism, mice tourism, business travel and other special tourism products to drive entertainment and shopping consumption.

\subsection{Guiding Tourists Consumption Reasonably}

First of all, Guangdong local governments should plan tourism product structure reasonably and at the same time pay attention to guide the tourists con- 
sumption tendency, plan rich type tourism products based on market supply and demand and adjust tourism consumption structure in meeting the demand of tourists, for example, advocating for good staff incentive travel, the benefits of tourism for low-income groups, in view of the students study tourism, silver for retirees.

Secondly, in addition to guide consumption tendency, tourism enterprises and the media units must strengthen the guide of tourism consumption content and guide the visitors to know the essence of the tourism consumption, increasing the demand and proportion of spiritual consumption.

Thirdly, the tourism enterprises need to innovate, based on the traditional sightseeing tourism products, put forward variety of tourism products system, and standardize guide's behavior, protect tourists' rights to visit and shop freely. If a guide occupies tourists too much time or transmits false information to tourists, it may lead to negative feelings, make tourist hate and even be fear of shopping, which are unfavorable for the healthy development of tourism businesses and reasonable consumption.

Finally, tourism enterprises and the media should intensify propaganda, let people to realize the importance of tourism consumption for life and work, and train their consciousness of tourism consumption.

\subsection{Deepening Regional Cooperation and Promote Tourism Brand}

Innovation of Guangdong tourism marketing needs to find a new fusion point. The core of the current tourism destination marketing tasks is actively responding to market demand, accelerating tourism enterprise brand construction with emphasis on the tourist spots, projects and other elements. Support the development of cultural tourism media companies and use film implanted, performing arts, animation and other multi-media to advertise tourism brand in Guangdong province. Make full use of new technologies, new media and new ways to build marketing system of Guangdong tourism.

First of all, implement the marketing strategy of "going out and come in", actively participate in the "Hong Kong, Macao and Taiwan" tourism economy cooperation, accelerate the construction and improve the cooperation mechanism of "Pearl River Delta" with "Hong Kong, Macao and Taiwan", form the development pattern of regional integration. Besides, strengthen the cooperation with the tourist generating region, build the regional cooperation pattern in "resource and customers sharing, information exchange, element flow, mutual benefit and reciprocity".

Secondly, stick to the mainstream media marketing, use radio, television, press publication, information communication and other modern media channels, continuously introduce new products, new luminescent spot, active marketing and create "vigor" Guangdong tourism brand through the creation of literature and art, film and television filming, blog, WeChat. Implement reward mechanism of tourism brand, reward enterprises which create high level scenic 
spots, star hotel, introduce the international famous brand and won the nation's top tourist.

Finally, optimize integration of marketing resources. Integrate tourism enterprise marketing fund from all levels of government in Guangdong, tourism enterprises and tourism estate business sponsored fund on the basis of voluntary, to explore setting up the Guangdong tourism marketing fund.

Tourism enterprise implement the mechanism of "replace subsidies with awards", activate the main tourism market, encourage enterprises to establish foreign tourism marketing center and tourism image store on tourist generating region, inject new vitality to the development of tourism in Guangdong.

\section{References}

[1] Jia, Y. (2008) Comparison Research on Inbound Tourism Consumption Structure of Six Hot Cities in China. Tourism Science, 3, 13-17.

[2] Yang, Z.Q. (2010) Research on Guilin's Tourism Industry Transformation and Structure Optimization. China Collective Economy, 27, 141-142.

[3] Chen, Z.F. (2009) Analysis of Domestic Tourism Consumption Structure of Fujian Province. Shanxi Higher School Journal of Social Science, 9, 43-46.

[4] Pang, T.T. (2010) The Problems Existing in the Domestic Tourism Consumption Structure in Anhui Province and Optimization. Journal of Shijiazhuang Railway University, 4, 27-30.

[5] http://www.gdta.gov.cn/

[6] Jiang, J.B., Liu, H.F. and Yan, M. (2014) Research on Tourism Transformation and Upgrading of Industrial Structure and Its Technological Innovation Path, Taking Guangdong Province as an Example. Journal of Chongqing University, 4, 16-24.

[7] Lin, N.Z. and Tao, H.J. (1994) Tourism Economics. Nan Kai University Press, Nanjing.

[8] Yuan, X.X. and Wang, Q.R. (2009) Thinking of Accelerating the Guilin Tourism Industry Transformation and Upgrading. Social Scientist, 12, 158-161.

[9] You, H. and Tao, Z.M. (2006) Research on Domestic Tourism Consumption Structure Existing Problems and Optimization. Jiangsu Business Theory, 8, 62-63. 